\title{
A arte e violência no olhar: Activismo feminista e desconstrução da violência contra as mulheres
}

The Art and Violence of the Gaze: Feminist Activism and the Decons-truction of Violence Against Women

L'art et la violence dans le regard : activisme féministe et déconstruction de la violence contre les femmes

\section{Maria José Magalhães}

\section{(2) OpenEdition}

\section{Journals}

Edição electrónica

URL: http://journals.openedition.org/rccs/3735

DOI: $10.4000 /$ rccs.3735

ISSN: 2182-7435

\section{Editora}

Centro de Estudos Sociais da Universidade de Coimbra

\section{Edição impressa}

Data de publição: 1 Junho 2010

Paginação: 89-109

ISSN: 0254-1106

\section{Refêrencia eletrónica}

Maria José Magalhães, «A arte e violência no olhar: Activismo feminista e desconstrução da violência contra as mulheres », Revista Crítica de Ciências Sociais [Online], 89 | 2010, colocado online no dia 01 outubro 2012, criado a 30 abril 2019. URL : http://journals.openedition.org/rccs/3735; DOI : 10.4000/ rccs.3735

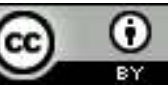




\section{A arte e violência no olhar: Activismo feminista e desconstrução da violência contra as mulheres'}

Este artigo vem na continuação do texto de Angélica Lima Cruz, retomando-se a questão da construção de um olhar que integra ou denuncia uma cultura de violência contra as mulheres. Aqui, explora-se como a crítica feminista da violência contra as mulheres desoculta os mecanismos da sua re/produção, mostrando também que a arte se pode constituir como processo de desconstrução desta violência. Para isso, apresentam-se e analisam-se algumas intervenções artísticas e instalações realizadas por feministas, quer no estrangeiro quer em Portugal, no activismo feminista do combate à violência contra as mulheres.

Palavras-chave: activismo; arte feminista; crimes contra as mulheres; cultura de violência; violência doméstica.

Arte e activismo feminista: desconstruindo a violência contra as mulheres Este artigo vem na continuação do texto de Angélica Lima Cruz, retomando-se a questão da construção de um olhar que integra ou denuncia uma cultura de violência contra as mulheres. Enquanto, no texto anterior, essa cultura está presente de modo subliminar, aqui exploram-se algumas formas de intervenção em que esta forma de violência é exposta. Assim, aborda-se o modo como a crítica feminista da violência contra as mulheres desoculta os mecanismos da sua re/produção, mostrando também como a arte pode constituir-se como processo de desconstrução. Para isso, apresentam-se e analisam-se algumas intervenções artísticas e instalações realizadas por feministas, quer no estrangeiro quer em Portugal, no activismo feminista do combate à violência contra as mulheres. Centramos a discussão em obras que, historicamente, têm contribuído para denunciar

\footnotetext{
${ }^{1}$ Este artigo teve o apoio do projecto PIHM/VG/0016/2008, financiado pela FCT em protocolo com a CIG: Amor, Medo e Poder: percursos de vida para a não violência/Love, Fear and Power: Pathways to a Non-violent Life.
} 
essa violência (sem pretensão de esgotar o tema), nomeadamente de Goya (Capricho 24, 1797-98), Nan Goldin (1984), Suzanne Lacy e Leslie Labowitz (In Mourning and In Rage, 1977), as Guerrilla Girls (How Women Get Maximum Exposure, 1989) e Paula Rego (1998), assim como em algumas intervenções feministas em Portugal concebidas por pessoas que, não sendo publicamente reconhecidas, têm trabalhado no campo artístico.

\section{A arte no activismo feminista}

O interesse feminista pela arte e pela história da arte decorre do nosso compromisso central com a vontade de compreender os lugares das mulheres e dos homens na sociedade contemporânea. Arte e história da arte têm um papel muito importante na formação das atitudes contemporâneas e na construção e produção de um olhar sobre a realidade social, na "formatação" das lentes com que olhamos essa realidade.

Se, enquanto feministas, queremos levar a cabo uma mudança social com tanta importância que se considere uma "revolução", como afirma Nochlin (1989), ${ }^{2}$ devemos trabalhar simultaneamente os fundamentos intelectuais e ideológicos em que assenta a construção do conhecimento e desocultar as ideologias subjacentes às instituições sociais, tais como casamento, trabalho, mass media, saúde e educação. As universidades e as relações entre o ensino superior e outras instituições, assim como as práticas sociais, devem fazer parte da investigação, quer como objecto, quer como um lugar para uma prática pedagógica e política que permitam criar dinâmicas e movimentos para a mudança.

Neste sentido, é tão importante a intervenção política pública mais tradicional (organizações políticas, manifestações), como intervir activamente nas universidades, uma vez que as tentativas de levar a cabo uma mudança social radical precisam de ser incluídas nos contextos académicos onde é produzido e transmitido o conhecimento. Em nossa opinião, isto implica uma análise histórica e crítica das questões intelectuais básicas, que o questionamento feminista ao status quo tem vindo a fazer. Aqui em análise, estão obras e intervenções de autoras reconhecidas e outras com menos reconhecimento público mas comungando de uma perspectiva de que a arte pode ser uma ferramenta poderosa de alerta e consciencialização, enquadrando-se no tipo de educação informal (La Belle, 1986). O argumento central é que as imagens, pinturas, cartazes, performances podem, para além de proporcionar uma experiência estética, contribuir para a desconstrução do sujeito dominador masculino.

\footnotetext{
${ }_{2}^{2}$ Originalmente publicado na Art News, 69, Janeiro, 1971.
} 
Conhecer a construção sociohistórica da relação entre as mulheres e os mundos da arte e destes com a sociedade mais alargada constitui um caminho possível para compreender as relações entre a produção artística e as relações sociais contemporâneas. Identificar os processos pelos quais as mulheres estiveram ausentes do cânone da arte requer, portanto, a reclassificação de categorias conceptuais básicas, no que concerne à educação artística, à articulação entre produção artística e públicos (mostras, exposições), assim como às relações com o mercado da arte.

Em ensaio já citado, Linda Nochlin (1989) começa por salientar a importância do conhecimento científico para o projecto político do feminismo. Em sua opinião, que partilhamos, não deve existir uma diferença simplista entre o activismo feminista, enquanto protesto ou organização social de oposição, e a reflexão sustentada e crítica do conhecimento. Estas duas dimensões são fundamentais para a concepção de feminismo que aqui se partilha, designadamente nos seus desafios ao poder patriarcal nas sociedades contemporâneas. Nesta ordem de ideias, a educação tem um papel importante, tal como é sublinhado por Linda Nochlin, ao realçar as relações assimétricas de poder no seu interior, educação entendida de uma forma abrangente 3 onde a autora inclui "tudo o que nos ocorre desde o momento em que entramos neste mundo" (1989: 150; ver também Harris, 2001). Na sociedade contemporânea, a exploração, subordinação e/ou opressão das mulheres ocorrem com o contributo deste processo de socialização, pela forma como são construídos os significados de "diferença sexual" mesmo a partir da primeira infância. Podemos aqui lembrar também Griselda Pollock (1988), ${ }^{4}$ que vem afirmar que o regime contemporâneo da "diferença sexual" depende muito da circulação de imagens, fotografias e filmes. A divisão sexual é, portanto, "o resultado da construção da "diferença sexual" como um eixo socialmente relevante do significado" (1988: 33).

Em termos da construção social dos significados, as feminilidades e masculinidades têm um lugar crucial, o que se constitui como relevante para o tema aqui em debate - a relação entre a arte e a violência contra as mulheres - quer no artigo de Angélica Lima Cruz, onde se realça a forma como a arte impediu as mulheres artistas de acederem ao cânone e contribuiu para a construção de um olhar predador, contribuindo, assim, para a produção

\footnotetext{
3 As ciências da educação têm vindo a desenvolver conceitos diferentes de educação, por exemplo, a partir de Thomas La Belle (1986), onde, para além da educação escolar, designada formal, emergem outros conceitos, como educação informal e educação não-formal, para explicitar processos sociais pedagógicos, onde se dá a produção, transmissão e recepção de conhecimento para além da instituição escolar. Não cabe no âmbito deste artigo explorar esta questão.

${ }^{4}$ Publicada originalmente em Block, 6, 1982.
} 
de uma cultura de tolerância da violência contra as mulheres - quer neste, onde se vai realçar a forma como a produção artística pode contribuir para a construção de uma lucidez que desafie e confronte essa mesma violência. O caminhar para esta lucidez pode passar pela subversão do que tem sido a construção do olhar da história, onde os/as oprimidas/as, derrotadas/os, frágeis, doentes, crianças, mulheres e velhas/os não têm tido voz. A violência contra as mulheres assenta também num olhar construído a partir de uma identidade social masculina, que dá relevância ao poder vitorioso, ao domínio, à conquista e ao controlo. Neste sentido, algumas autoras e alguns autores têm evidenciado a ligação estreita entre a violência contra as mulheres e a construção social das masculinidades (ver Hatty, 2000), articulada com a construção moderna de um "eu imperial", ${ }^{5}$ um sujeito racional, auto-suficiente, no controlo das suas forças internas e externas. Obviamente, este "eu imperial" é masculino e a violência é uma das suas prerrogativas. A este propósito, Suzanne Hatty afirma que "na oficina histórica e cultural da masculinidade", o jovem do sexo masculino aprende que apenas será sujeito se conseguir o domínio de si e do contexto. Os processos de socialização ${ }^{6}$ ensinam aos rapazes que devem utilizar a força, mesmo se necessário a violência, caso não consigam o que pretendem. Nas palavras de Suzanne Hatty:

Claramente, a violência é ainda a prerrogativa do jovem do sexo masculino, especialmente quando confrontado com as contradições e os paradoxos do desejo contrariado e da ausência de poder social e pessoal. Indo mais fundo dentro da oficina histórica e cultural da masculinidade, um jovem pode sempre recuperar a última ferramenta da auto-assertividade masculina: o poder através da violência. (Hatty, 2000: 6)

A masculinidade hegemónica liga-se estreitamente a noções de poder, domínio, propriedade e força, componentes que são parte integrante do "macho man". Trata-se de características que atravessam todas as classes sociais, contrariamente à representação veiculada pelos mass media que tende a acentuar a associação entre violência e masculinidade nas classes mais desfavorecidas. Este ideal masculino poderoso enraíza-se igualmente numa noção moderna de um "eu", onde as crenças culturais definem os parâmetros de uma experiência humana assente num "eu" estável, coerente, dominador, dono de si mesmo (e de outras/os), no controlo do seu próprio

\footnotetext{
${ }^{5}$ No original, imperial self.

${ }^{6}$ Como processos de socialização subentendemos um conjunto de instituições, de mecanismos, como a televisão, os jogos, os pares, a família, a escola, a internet, entre muitos outros.
} 
corpo e mente, e, claro, no domínio da razão. É esta razão, ligada às noções do controlo e da propriedade, que legitimam, a este "eu", a capacidade de produzir a verdade - a sua verdade, assente nas vozes da autoridade e da legitimidade que o Estado, a ciência, a igreja e a tradição têm endossado ao sujeito patriarcal, dono da esfera privada e autónomo e independente na esfera pública. Este "eu" que, como Giddens (1991) refere, é um "eu" moderno enquanto projecto reflexivo do qual o indivíduo é responsável, e é também compreendido enquanto limitado por fronteiras corporais, onde o autocontrolo e a autodirecção, assim como a independência e a auto-suficiência, constituem itens essenciais para a sua assunção. Voltando a citar Suzzane Hatty, este "eu"

é o epítome $[\ldots]$ da modernidade na subjugação infindável da natureza, na exclusão da contingência e na rude imposição da ordem e da previsibilidade. [...] A violência, ao serviço do "sujeito" moderno, preserva a individualidade e evita os fracassos e a possibilidade da sua fusão com o perigoso não-sujeito. A violência, enquanto estratégia moderna, garante tanto o controlo individual como o controlo social, e, ao mesmo tempo, mantém e perpetua a hierarquia e a desigualdade. (idem: 10)

Podemos ver os mecanismos evidenciados nos processos de vitimização de mulheres nas relações de intimidade através deste modo de incorporar a mulher como Outro, assimilá-la a si mesmo, querer fazer dela a extensão do seu próprio corpo, mas a ideia é a de forçar a Outra a ser o que ele quer, negar a fronteira que o separa da Outra. Suzanne Hatty desenvolve esta noção de um "eu imperial", que consideramos relevante para reflectir sobre a violência contra as mulheres nesta sociedade (ver também Benjamin, 2004):

Este sujeito, autónomo, auto-suficiente, com uma identidade fixa e previsível, é [...] também narcísico, materialista e expansionista; neste sentido, exploração, manipulação e colonização do mundo natural e social tornam-se forças aliadas. As dimensões narcísicas do "eu imperial" manifestam-se na preocupação com o cultivo de uma imagem de acordo com os símbolos socialmente construídos de perfeição, status e sucesso. O corpo, as relações e o próprio conhecimento tornam-se objectos para serem explorados. De facto, o "eu imperial" da era moderna tem um apetite voraz para expandir o seu domínio e o seu território de controlo, a fim de suprimir todos os seus competidores e conseguir o poder total. (Hatty, 2000: 11)

Como a análise feminista tem mostrado e as histórias de vida das mulheres vítimas de violência doméstica têm evidenciado (cf. Magalhães, 2005), estas características de independência, autoconfiança, auto-regulação e 
autocontrolo, implícitas no individualismo que subjaz ao sujeito moderno, não são extensíveis a todas as pessoas: apenas aos seres humanos do sexo masculino. Por seu turno, a dependência na cultura ocidental, incluindo na ciência, tem sido conceptualizada como imaturidade ou deficiência emocional e associada à feminilidade. O significado de "dependência" está associado a tudo o que é mulher, o valorizado constructo de independência tem estado associado ao exercício da masculinidade na esfera pública (Pateman, 1988/2003), sendo os direitos e privilégios do cidadão no Estado moderno exemplos dessa emblemática independência (cf. Pinto et al., 2002). O medo da perda e a dificuldade de lidar com as frustrações são tão profundos, o ethos do controlo está tão entrincheirado na sociedade ocidental moderna, que torna, para este sujeito masculino, muito difícil lidar com as experiências individuais de trauma e de perda: perda de autocontrolo, perda da saúde, perda de um ente querido, perda de prosperidade material. Como afirma Hatty (2000: 12), o efeito da perda é lembrar ao "eu” a sua finitude e mortalidade, algo que o "eu" imperial não consegue admitir. Simultaneamente, esse "sujeito imperial" despreza os seres que evidenciam (ou quando evidenciam) fragilidade e finitude. ${ }^{7}$

Gravidez e maternidade, amamentação e o cuidado das crianças serão marcas no não-sujeito moderno, marcas de forças obscuras e incontroláveis por esse sujeito auto-suficiente e dominador: constituem as grandes marcas da diferença sexual, sobre as quais o falocentrismo tem construído uma cultura de violação e violentação das mulheres. Estas dimensões da vida, consideradas insignificantes por uma cultura dominante, estão também ausentes nas representações artísticas na história da arte. No entanto, vale a pena sublinhar algumas das poucas excepções que podem ser identificadas como contribuição da arte para iluminar e desafiar as formas de violência contra as mulheres, no pressuposto de que, como afirma Deborah Haynes, "a arte tem o poder de mudar a consciência e, em última análise de afectar a mudança social" (Haynes, 1997: 58). Para além do caso do quadro de Artemisa Gentileschi, Susana e os Velhos (1610), ${ }^{8}$ até ao século XX apenas identificámos o trabalho de Goya como exemplo deste contributo.

\footnotetext{
${ }^{7}$ Não será por acaso que, em muitas histórias de vida de mulheres vítimas de violência, podemos verificar que o grande marco da agressão é muitas vezes a gravidez da mulher, muito embora tenha havido muito cedo sinais da violência futura.

8 Também referida no artigo de Angélica Lima Cruz e ainda em Cruz e Magalhães (2009), como um dos escassos exemplos em que uma situação de violência contra a mulher representa a figura feminina de forma claramente sofredora e subjugada, diferentemente de outras pinturas em que Susana manifesta evidente prazer (ver também Garrard, 1982).
} 


\section{Goya e a denúncia da violência contra as mulheres como parte da sua crítica social}

Se a memória é também muito importante na construção da(s) história(s) das opressões, vale a pena igualmente recordar as formas de denúncia dessas opressões. No que se refere às mulheres e à arte, esta memória é ainda mais indispensável pela escassez de referências artísticas relativas a esta denúncia social. Podemos referir, aqui, a gravura de Goya intitulada "Eles levaram-na" [fig. 1], que pertence à série Caprichos (Hagen e Hagen, 2004: 35), cujo título talvez se relacione com o facto de o artista, a partir de 1793, ter começado a abordar a crítica social. Esta crítica social, em tempos conturbados da Revolução Francesa, ocorrida no país vizinho ao seu, teria que ser recebida como "eventuais fantasias", ou seja, algo aparentemente para não ser levado a sério. No entanto, eram alertas para problemas sociais. Esta gravura em concreto denuncia a violência dos homens exercida sobre as mulheres, situações em que os perpetradores permanecem anónimos e, por isso, incólumes, o que habitualmente acontece em casos de guerra.

Para além da denúncia da violência contra as mulheres perpetrada pelos homens, outras obras de Goya, já no início do século XIX, da série intitulada Desastres da Guerra (Aguilar, 2007: 30), denunciam igualmente os horrores da violência da guerra, onde as mulheres são também grandes vítimas. Nestas obras de Goya, a mulher é sujeito (embora vítima) da acção representada, e não mero objecto de contemplação de um público. Entre estas obras referidas e os anos 1960/70, não identificámos, até ao momento, outras obras que sejam representativas da denúncia da violência contra as mulheres. Estas décadas são também o momento da emergência do movimento feminista de segunda vaga, em que as mulheres se afirmam como produtoras e autoras.

Data desta época a contestação do cânone modernista e a abordagem formalista na crítica artística. Como afirma Deborah Haynes (1997), "através de diversos modos inovadores, as mulheres contestaram o cânone modernista e a crítica formalista que, em termos teóricos, apoiava esse cânone” (1997: 141). Além disso, a ruptura da divisão entre "cultura erudita" e "cultura popular" (Frow, 1995), a relação entre status e autoria feminina (ver também Cruz, 2002), a mercadorização da cultura e a comercialização das artes, aliadas à polarização da cultura contemporânea em torno de questões de etnicidade, "raça", sexo e outras diferenças, propiciaram a emergência de novos media em arte, como instalações, performances e outras formas de exploração multimédia. De entre as diversas obras de mulheres e/ou feministas, podemos identificar algumas que se debruçaram sobre o tema aqui em debate. Seguiremos com a análise dos trabalhos de Suzanne Lacy e Leslie Labowitz (1977), Nan Goldin (1984), Paula Rego (1988) e Guerrilla Girls (1989). 


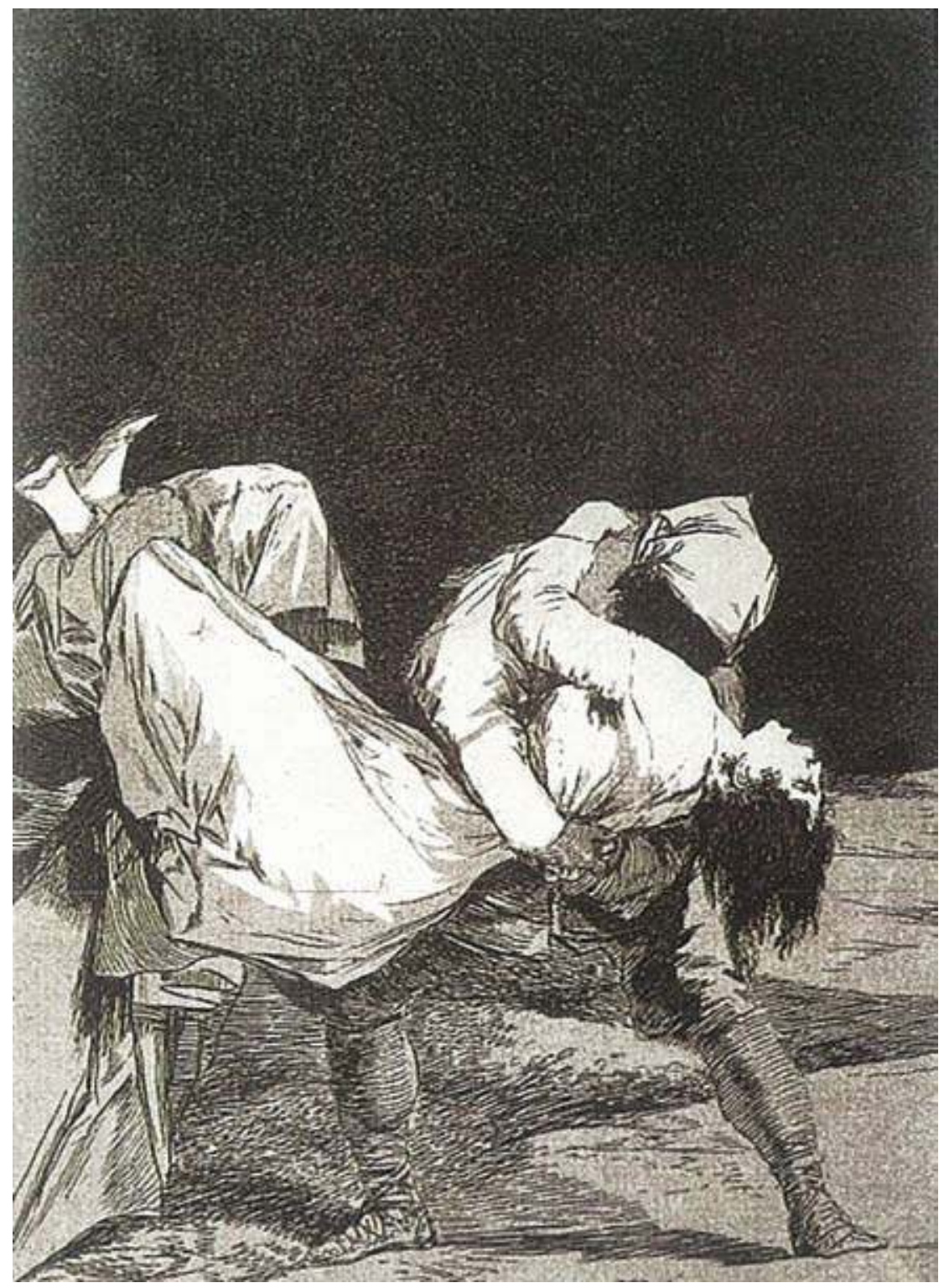

FIGURA 1 - Goya, Eles levaram-na (Série Caprichos), 1797-1798 


\section{Suzanne Lacy e Leslie Labowitz, 1977, In Mourning and In Rage}

Em 1977, e na sequência de diversos casos de violação e estrangulamento de pelo menos dez mulheres em Los Angeles, ${ }^{9}$ Suzanne Lacy e Leslie Labowitz prepararam uma performance para alertar a opinião pública e os mass media para o problema social da violência contra as mulheres ${ }^{10}$ (Labowitz-Starus e Lacy, 1978/2006). A imprensa da época noticiou que "[c]inquenta mulheres cobertas de negro chegaram de mota em frente à Câmara Municipal da cidade de Los Angeles" (Haynes, 1997: 48), exibindo faixas com "In memory of our sisters" ("Em memória das nossas irmãs") e "Women Fight Back" ("As mulheres reagem"). Pretendiam dirigir-se aos representantes dos media, aos activistas da comunidade e aos políticos para denunciar a disseminação da violência contra as mulheres, desde a violação e o incesto às imagens agressoras da publicidade. Estas duas artistas e activistas planearam uma performance intitulada In Mourning and In Rage [fig. 2] que tinha por objectivo, tal como referem Norma Broude e Mary Garrard, usar os próprios media como meio de subversão das mensagens dominantes na época: ou seja, que os meios de comunicação passassem a introduzir, nas notícias, elementos de análise feminista na cobertura dos casos de violência contra as mulheres, e não colocassem a ênfase exclusivamente no agressor (Broude e Garrard, 1994: 149). Segundo diversas autoras, esta acção teve tanto impacto e eficácia que puderam ser observados numa série de eventos subsequentes. Por exemplo, a companhia de telefones, que previamente tinha recusado colocar na lista dos números de emergência o número de uma linha verde de apoio às vítimas de violação, afirmou, mais tarde, querer mudar a sua posição, passando a colocar este número no local onde estavam os outros números de emergência. Outro exemplo: uma deputada municipal comprometeu-se a ajudar a criar cursos de autodefesa para mulheres, sobretudo para as que estavam empregadas. ${ }^{11}$

\footnotetext{
9 Estes crimes ficaram conhecidos como o caso "Hillside Strangler".

${ }^{10}$ Suzanne Lacy e Leslie Labowitz prepararam uma performance na sequência da décima mulher violada no caso "Hillside Strangler", performance que pretendia ser igualmente um evento mediático. Esta acção, simultaneamente artística e política, tinha a intenção de alertar os mass media para a forma como as vítimas eram retratadas na imprensa, insistindo que o facto de as mulheres assassinadas terem sido prostitutas não deveria diminuir a gravidade do crime. Chamaram também a atenção para o facto de esta violência - a violação por um estranho - não ser um tipo isolado de violência nem necessariamente perpetrado por um estranho, exigindo, assim, o reconhecimento das diferentes formas de violência contra as mulheres, igualmente por homens próximos, como maridos, namorados e pais, e alargando este conceito também ao assédio no trabalho e à objectificação exercida pelos mecanismos de socialização e de marketing, nomeadamente a publicidade sexista e humilhante. ${ }^{11}$ A ideia que estava disseminada na época era a de que as mulheres sofrem violência sobretudo se saírem de casa e forem trabalhar; o movimento feminista e o movimento das mulheres vítimas de violência e das casas-abrigo têm vindo a conseguir mudar este mito, através da apresentação de dados e análise da realidade empírica.
} 


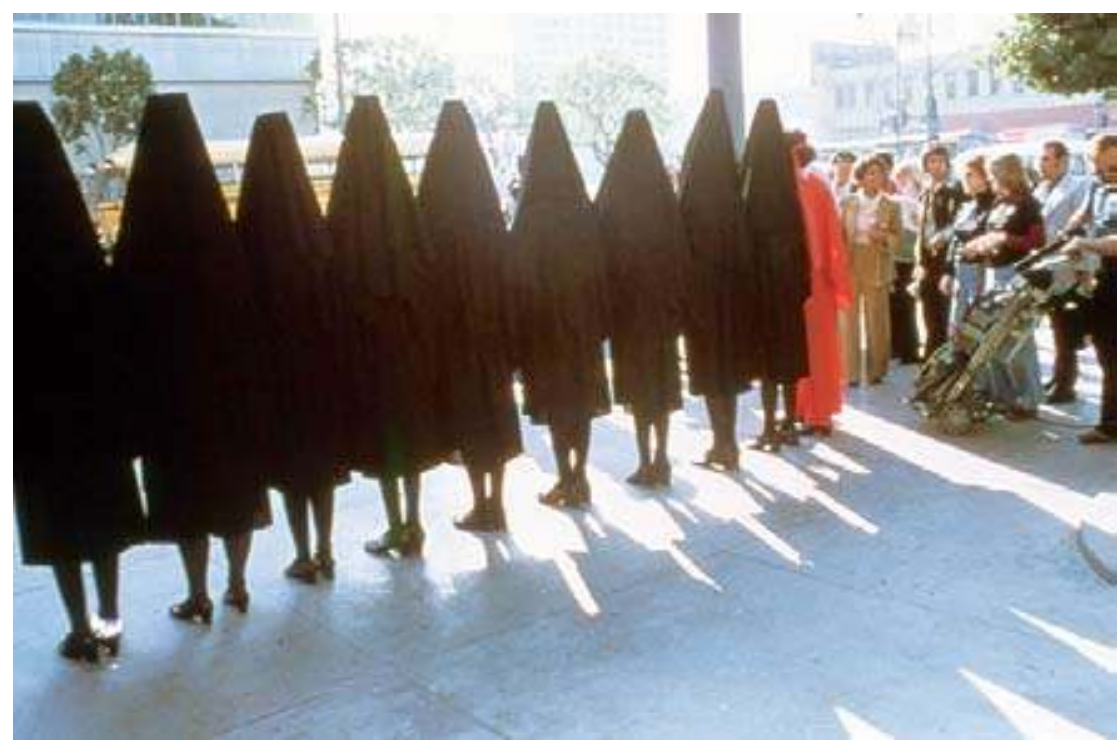

FIGURA 2 - Leslie Labowitz and Suzanne Lacy (1977), In Mourning and in Rage, Los Angeles

Esta performance exemplifica um importante dictum feminista: "O pessoal é político"; demonstra ainda que, quando criada em colaboração com a estética e a política, a arte é uma poderosa ferramenta para mudar a consciência colectiva e criar mudança social. ${ }^{12} \mathrm{Em}$ algumas imagens divulgadas acerca deste evento, podem ver-se faixas e cartazes com frases como "In memory of our sisters", reclamando o conceito de sisterbood [sororidade], apelando à solidariedade entre mulheres, à consciencialização de que, quando uma mulher é vítima de violência, somos todas as mulheres um pouco mais vitimizadas. Noutras, aparece ainda "women fight back", como apelo à acção, à não aceitação passiva dos atentados à dignidade física, mental ou moral das mulheres.

\section{Nan Goldin, 1984 - a experiência pessoal de vitimização retratada}

Um exemplo ainda mais gritante do referido princípio feminista é o trabalho de Nan Goldin, uma fotógrafa que se assumiu como vítima de violência doméstica (marital). Goldin é uma das artistas incluídas no realismo social nas artes visuais, documentando facetas muito diversas da cultura e da sociedade contemporâneas. Concretamente no que aqui

${ }_{12}$ Ver site da UMAR (Quem somos - Galeria de Imagens, p. 7): http://www.umarfeminismos. org/index.php?option=com_content $\&$ view=article\&id=48\&Itemid=35\&limitstart=6. 
está em análise, a experiência de violência doméstica sofrida pela própria artista encontra-se documentada na sua obra (1984). ${ }^{13}$ Coerente com a perspectiva do realismo social e com o objectivo de tornar público este problema, não tenta disfarçar as equimoses, embora use batom e jóias. Entre o batom e as jóias, por um lado, e as equimoses por outro, este trabalho explora as pressões a que as mulheres estão sujeitas sob a capa do aspecto exterior para serem mais atractivas aos parceiros, que por vezes as deixam marcadas, no corpo e na alma, não apenas de equimoses e feridas físicas, mas sobretudo de medo. Anos mais tarde (s/d), já depois do divórcio, Goldin retrata-se novamente, sendo possível observar como a saída da vitimização ${ }^{14}$ lhe libertou o corpo e a mente. Como muitas outras de nós, é caso para dizer, "vale mais sozinha do que mal acompanhada". $\mathrm{Na}$ desconstrução da violência contra as mulheres nas relações de intimidade, este é um grande ditado a recuperar para contrapor a um outro mito ainda muito presente na nossa sociedade: "uma mulher não é ninguém sem um homem" (Dickson, 2003).

\section{As Guerrilla Girls e o combate à invisibilidade das mulheres (1985)}

Num manifesto-performance de 1985, agora famoso, as Guerrilla Girls mostram que, no Metropolitan Museum (Nova Iorque), apenas 5\% do conjunto dos artistas são mulheres enquanto $85 \%$ dos nus são femininos (Freeland, 2001). Este cartaz teve algum impacto, também porque foi seguido da sua reprodução em revistas e em autocolantes que eram afixados em vários locais, inclusivamente nas casas de banho de museus e teatros. Elas voltam a sublinhar o facto de que, mais tarde, em 1997, no MOMA, ${ }^{15}$ a ausência das mulheres artistas continua a verificar-se: entre os 75 artistas ali representados, apenas 4 eram mulheres. Com ironia mordaz e "picante", constituem uma forma de sátira social feminista. ${ }^{16}$

As Guerrila Girls têm funcionado como um poderoso ícone para as jovens mulheres artistas, feministas ou não, que se vêem num meio social cheio de contradições. Se, ao longo do século xx, foram crescendo a legislação e o discurso da igualdade, o certo é que, nas instituições e nas práticas sociais, esta está longe de ser concretizada. Práticas sociais, umas

\footnotetext{
${ }_{13}$ Ver Uta Grosenick (2001).

${ }^{14}$ No contexto da violência contra as mulheres nas relações de intimidade, a situação vivenciada pelas vítimas é, habitualmente, um processo longo, em que a mulher se encontra no que Lenore Walker designou como síndrome da mulher maltratada (1977), pelo que temos vindo a utilizar a noção de vitimização para designar esta condição (Magalhães, 2005).

${ }_{15}$ MOMA - Museum of Modern Art, de Nova Iorque.

${ }_{16}$ Veja-se, por exemplo, o texto que escrevem sobre as vantagens de ser mulher artista: http://www. guerrillagirls.com/posters/advantages.shtml.
} 
mais veladas, outras mais ostentatórias, continuam negando às raparigas, às jovens e às mulheres o seu lugar no mainstream. Usando o nu feminino e denunciando a objectificação a que o corpo das mulheres tem sido sujeito ao longo da história da arte ocidental, protestando contra os bloqueios à entrada das artistas, por seu próprio mérito, nos fóruns de reconhecimento do seu trabalho, elas constituem, hoje, uma referência para todas nós. O grande impacto do trabalho deste colectivo é iluminar a forma como as mulheres estão presentes / ausentes no mundo artístico. Elas tornam visível a instrumentalização do corpo das mulheres enquanto forma, cuja objectificação nos despersonaliza, evidenciando, neste processo, como as artistas, por serem mulheres, têm tido mais dificuldade em ver o seu trabalho reconhecido. $\mathrm{O}$ meio utilizado - a performance em que habitualmente aparecem nuas com máscaras de gorilas, usando a paródia e o humor ${ }^{17}$ tem tido uma poderosa influência na mudança de relações entre as mulheres e o mundo das artes (eruditas).

\section{Paula Rego, 1998, Sem Título - a mulher como au(c)tora}

Uma das séries de Paula Rego, que podemos trazer para reflexão, é a série sobre o aborto, à qual ela não atribui título ([fig. 3] Sem Título, 1998). Um título que recusa nomear o inominável - o aborto clandestino, os corredores de morte ou de doença de mulheres por imposição de um regime social masculino que se rege por uma racionalidade abstracta e uma ética desencarnada,${ }^{18}$ a qual se não enraíza nas vidas concretas das pessoas, neste caso, das mulheres. Germaine Greer (1979) escreveu sobre Paula Rego que "os seus quadros têm uma subversão profunda. Não há nada previsível, são todos espontâneos. Ela não pertence a uma determinada escola. Ela pensa com imagens - algumas delas, as mais extraordinárias e distorcidas que já vi” (Greer, 1979: 23).

Nesta série, as mulheres recolhem-se numa solidão dorida e secreta. Feita em 1998, aquando do $1^{\circ}$ Referendo em Portugal sobre a Interrupção Voluntária da Gravidez (IVG), a série confirma a revolta expressa pela própria autora a propósito da criminalização das mulheres por motivo de aborto. De notar que Paula Rego expôs estas obras, no Porto, entre finais

\footnotetext{
${ }^{17} \mathrm{http}: / /$ www.guerrillagirls.com/posters/getnaked.shtml.

${ }^{18}$ Barbara Marshall (1984) mostra como a modernidade se constrói na ideia de uma racionalidade abstracta que, assentando aparentemente num sujeito universal, efectivamente se baseia num falso neutro (Barreno, 1985), ignorando as condições materiais da existência, as experiências e subjectividades sexuadas, racializadas e atravessadas pela classe social. O debate social em torno do aborto é um dos exemplos paradigmáticos da tensão entre este tipo de racionalidade e uma outra, que podemos designar por comunicacional (Fraser, 1995).
} 


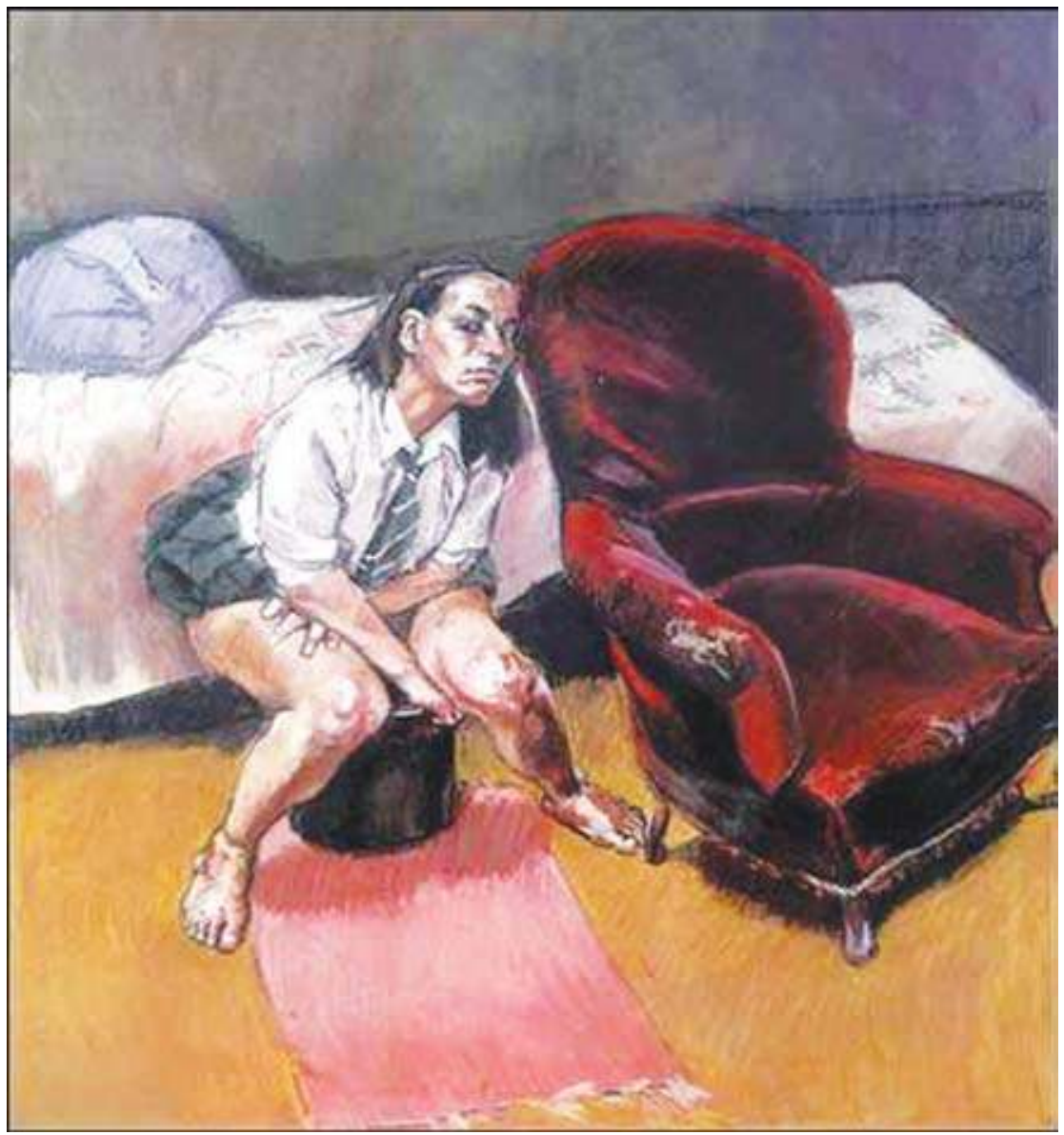

FIGURA 3 - Paula Rego, Sem título, 1998

de 2001 e inícios de 2002, na altura do conhecido "Julgamento da Maia". ${ }^{19}$ Como refere a imprensa portuguesa da época, para Paula Rego, a violência começa no nascimento e acaba na morte, e o sexo tem, por vezes, implicações brutais. ${ }^{20}$ As figuras de mulheres, deitadas, ajoelhadas, de costas, absortas ou activas, mostram que o sexo é um impulso vital que envolve o trauma do nascimento, ou o incómodo da menstruação e o drama do aborto.

\footnotetext{
${ }^{19}$ O "Julgamento da Maia", como ficou conhecido, decorreu de Outubro de 2001 a 18 de Janeiro de 2002, e consistiu num processo de acusação de 43 arguidos/as, entre os quais 17 mulheres por terem abortado, uma enfermeira, Maria do Céu, que os praticava, um médico, um assistente social, um taxista, entre outros profissionais, que colaboraram para ajudar as mulheres que procuravam abortar. ${ }^{20}$ Entrevista a Paula Rego (1997), Público, 16 de Maio, Lisboa.
} 
Esta série de Paula Rego deu um contributo forte à luta contra aquela violência da clandestinidade a que as mulheres estiveram sujeitas, em Portugal, até 2007. As suas obras expostas nessa altura foram um modo poderoso de denúncia e de protesto social, no que teve um papel crucial a forma como a comunicação social deu voz às pinturas e à pintora nas primeiras páginas de alguns jornais diários e em diferentes canais de televisão. ${ }^{21}$ Mais ainda, constituiu um signo poderoso em contraposição ao "zezinho" e outras imagens dos fetos que o movimento anti-escolha divulgou na altura do $1^{\circ}$ referendo e repetiu ad nauseam no $2^{\circ}$. Enquanto o movimento pro-choice nos Estados Unidos teve uma imagem forte na luta pela despenalização do aborto (a fotografia do cadáver de Geraldine Santoro, vítima de aborto clandestino, publicada, pela primeira vez em Ms. Magazine, em 1973), muitas investigadoras activistas do feminismo e concretamente desta luta em particular têm referido o poder das imagens usadas pelos anti-escolha e a dificuldade por parte dos Movimentos SIM em usar imagens igualmente poderosas. ${ }^{22}$

\section{Arte e activismo: construindo a agência feminista}

Apresentamos agora alguns exemplos da utilização de trabalhos artísticos em intervenções feministas, umas mais públicas e claramente políticas no sentido tradicional, outras igualmente políticas, mas em sentido mais alargado, embora em âmbitos sociais restritos e com pequena dimensão em termos de visibilidade pública. Nos casos que a seguir apresentamos, queremos salientar a forma como as ferramentas artísticas e estéticas são utilizadas pelo movimento feminista para criar lucidez sobre a violência contra as mulheres, mas também para incentivar à acção política (no seu sentido lato) individual e colectiva para estabelecer a agenda política no sentido da mudança social, noção que temos vindo a designar como agência (Magalhães, 2003; 2007).

\section{Intervenção “O Meu Corpo Pertence-Me”, Porto 2001-02}

Entre 2001 e 2002, o Porto assistiu a uma intervenção anónima, na altura do Julgamento da Maia (já referenciado) e realizada por uma cidadã do Estado Espanhol, que trabalhou durante algum tempo nos "Maus Hábitos”, um bar da cidade do Porto. Foi uma intervenção em que a artista

\footnotetext{
${ }^{21}$ Mais tarde, em 2004, Paula Rego vem a expor em Serralves, onde a série Aborto esteve incluída. ${ }^{22}$ Karyn Sandlos (2000) analisou a utilização de imagens de fetos nas campanhas dos movimentos anti-escolha, nos Estados Unidos, e fez o contrapondo com a forma como os movimentos pró-escolha usaram a foto de Geraldine Santoro, que apareceu morta num quarto de um hotel, em 1972, depois de se ter esvaído em sangue em consequência de um aborto clandestino.
} 


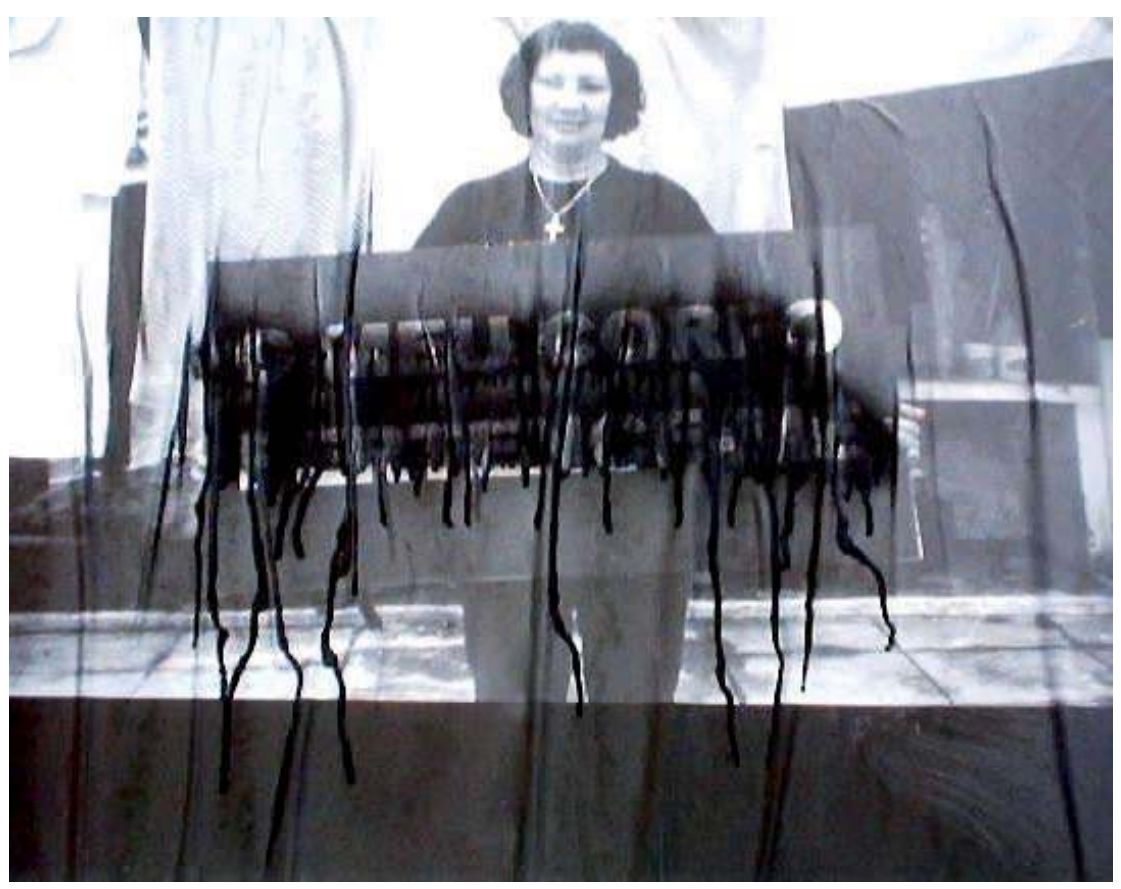

FIGURA 4 - Anónima (2001-2002), O Meu Corpo Pertence-me

falava com mulheres populares da zona do Bolhão (onde se situa os "Maus Hábitos") e, em seguida, fotografava-as com um cartaz a dizer "O MEU CORPO PERTENCE-ME", como exemplifica a imagem da figura 4 um dos cartazes expostos. A partir destas fotografias, a fotógrafa realizou diversos cartazes a preto e branco que afixou pela baixa portuense. $\mathrm{Na}$ altura, o que nos despertou a atenção foi o facto de os cartazes não resistirem um dia na parede e serem muito rapidamente rasgados, pintados, ou invisibilizados por outros colados por cima. $\mathrm{Na}$ figura referida, pode ver-se como as rajadas de tinta acabaram por quase anular a frase da mensagem. A quantidade de tinta atirada para cima do cartaz, o número de rasgões em tão pouco tempo, assim como a colagem de outros papéis e cartazes por cima permitem-nos deduzir a intenção de censurar a mensagem.

A propósito do "Julgamento da Maia", foi possível ao movimento feminista português, com realce para o papel da "Plataforma pelo Direito de Optar", colocar o aborto na agenda política, voltando ao debate sobre a capacidade e o direito das mulheres de decidirem sobre as questões relacionadas com o seu corpo, neste caso, em matéria de saúde reprodutiva. Esta simultaneidade temporal não terá sido, pensamos, alheia à reacção provocada. 
Homenagear mulheres assassinadas por violência doméstica $(2004,2006,2008)$ Em 2004, a UMAR criou o Observatório de Mulheres Assassinadas por violência em relações de intimidade e, no dia 25 de Novembro desse ano, comemorando o Dia Internacional pela Eliminação da Violência Contra as Mulheres, realizou uma instalação, em homenagem às mulheres assassinadas nesse ano. A instalação foi realizada na Praça da Batalha, no Porto, onde foram coladas "manchas" no chão, de papel vermelho plastificado, com os nomes das mulheres, idade e o tipo de relação (casamento, união de facto, namoro) que mantinham ou tinham mantido com a pessoa por quem foram assassinadas. Contrariamente à tendência geral, sobretudo da comunicação social, cujo protagonismo é dado aos agressores, como Artemisa Coimbra demonstrou (2008), esta homenagem pretendeu lembrar, nomeando-as, as mulheres que viram o seu curso de vida tão brutal e inutilmente aniquilado.

Sobre as mulheres assassinadas por violência nas relações de intimidade, realizou-se ainda, em Outubro de 2006, em Almada, uma outra instalação recorrendo aos dados do Observatório de Mulheres Assassinadas relativos a 2005. As árvores da Praça S. João Baptista foram parcialmente envolvidas com grandes panos negros e cartazes a preto e branco afixados nessas árvores mostravam o número e idade de mulheres assassinadas, o perfil do agressor, assim como o tipo de relação com a vítima e a arma utilizada. Em Fevereiro de 2008, uma instalação e performance tem os mesmos objectivos, realizando-se, desta vez, no Porto. ${ }^{23}$ Um número de mulheres igual ao número de mulheres assassinadas em 2007, vestidas de negro e com as cabeças envoltas em panos negros, jaziam deitadas numa lona preta onde foram coladas "manchas" de papel plastificado vermelho com os nomes das mulheres, idades e tipo de relação com o presumível homicida. Do alto do $3^{\circ}$ piso do $n^{\circ} 250$ da Rua do Paraíso, desfraldou-se um enorme pano preto com letras brancas coladas, informando o número de mulheres assassinadas e as tentativas de homicídio daquele ano. Qualquer uma das acções referidas não teve impacto na comunicação social, dado que os mass media apenas relataram os dados apresentados. No entanto, ajudaram quem passava a visualizar o problema a ter uma noção mais concreta do significado do femicídio em relações de intimidade, contribuindo também para uma maior implicação por parte de quem participou nestas intervenções.

\footnotetext{
${ }^{23}$ Ver site da UMAR (Quem somos - Galeria de Imagens, pp. 7 e 4): http://www.umarfeminismos.org/index.php?option $=$ com_content $\&$ view $=$ article\&id $=48 \&$ Itemid $=35 \&$ limitstart $=6$; http://www.umarfeminismos.org/index.php?option=com_content\&view=article\&id=48\&Item $\mathrm{id}=35$ \&limitstart $=3$.
} 


\section{Uma nota final: um contributo da arte na construção de um mundo também feminista}

A ligação entre o poder e a construção do significado tem um papel crucial na definição da hierarquia simbólica das diferenças culturais ${ }^{24}$ nas relações de dominação e subordinação, à volta das quais a cultura ocidental se organizou, o que tem sido reflexão de pensadores mais recentes, desde Foucault (2001) e Stuart Hall (1997) a Drucilla Cornell (2009) e bell hooks (1995). Estas análises sobre a forma como o poder é exercido - não através de uma repressão aberta, mas através de investimentos em instituições particulares e discursos, e as formas de conhecimento que eles produzem têm levantado muitas questões acerca do funcionamento da cultura visual como uma prática definida e regulada sobre o lugar das mulheres na história da arte (Chadwick, 1996).

Neste artigo, tentámos mostrar como a arte, articulada com a política feminista, pode ser uma poderosa ferramenta para a transformação social. Concretamente, foi aqui discutido o caso das ideias e representações sociais sobre a violência contra as mulheres. Esteve aqui em discussão o argumento de que o sujeito moderno masculino e dominador é produzido por um conjunto de forças e mecanismos sociais, sendo necessário desafiar esta construção social, se queremos produzir mudança social. Nesta ordem de ideias, a luta contra este tipo de construção social não pode assentar apenas em tradicionais formas de acção política: as formas de acção têm de ser mais "produtivas", contribuindo para a construção de novas subjectividades e operando a mudança, simultaneamente, aos níveis individual e colectivo. Também Griselda Pollock (2007) defende que a arte feminista "deve criar um tipo de espectador completamente novo como parte integrante das suas estratégias figurativas" (2007: 103). ${ }^{25}$ É também neste conjunto de estratégias que podemos incluir as performances e instalações utilizadas por feministas para consciencializar acerca das diversas dimensões da subordinação das mulheres, entre as quais a violência em relações de intimidade.

Reconhecemos, no entanto, que as feministas estão divididas por "feminismos" diferentes e, nessa medida, também por uma variedade de princípios

\footnotetext{
${ }^{24}$ Podemos citar, entre outros e outras, John Frow (1995), que discute as oposições entre cultura erudita e cultura popular e as mudanças na estrutura social que temos vindo a observar no que se refere ao papel do conhecimento e da produção artística. Os grupos sociais diferentemente posicionados na estrutura social (classe social, sexo, raça) participam nos processos de dominação, na medida em que esta é exercida através de processos de socialização que implicam a adesão, não apenas cognitiva, mas também emocional, à criação da hegemonia. Estes processos mostram como a produção do significado se faz a partir dos lugares cimeiros da estrutura social. No entanto, esta produção compete, em termos culturais, com as formas diferentes e divergentes de recepção e, simultaneamente, com formas subversivas de utilização e produção.

25 Estamos a citá-la a partir de $A$ Batalla dos Xéneros (2007).
} 
com expressão nos modos como trabalham os símbolos culturais e como se propõem, no argumento de Hélène Cixous, romper com o estabelecido e projectar o ainda improjectável (Cixous, 1975/2006). Lucy Lippard (1995) refere uma outra questão que nos parece crucial para equacionarmos a transformação social em direcção a um "mundo também feminista", a saber, que a relevância internacional do feminismo se baseia em parte na capacidade de identificação que as mulheres potencialmente podem ter com "todos os/as oprimidos/as e sem privilégios" (1995: 151). Hoje, e tal como Parker e Pollock (1981) já o fizeram, talvez já não interesse tanto identificar ou reclamar uma identidade ou essência separada para as mulheres - perspectiva mantida por algumas feministas "separatistas", chamadas também de "radicais" nos anos 1970 e 1980, da qual fez parte a autora deste texto Rozsiska Parker e Griselda Pollock constroem uma compreensão "relacional" do que é "ser" homem ou mulher. Baseiam-se num sentido de história comum da humanidade, uma perspectiva compartilhada pelos/as marxistas. As feministas não podem separar as mulheres desta história comum e desta posição social, "fora do processo histórico de que os homens e as mulheres indissoluvelmente fazem parte" (1981: 107).

A história de arte feminista deve considerar-se parte da iniciativa política do movimento feminista, não só como uma nova perspectiva artístico-histórica, com o objectivo de complementar a história de arte existente, mas igualmente com o compromisso com a política do conhecimento. Se a arte tem poder, ainda que nem sempre directamente, o movimento feminista pode incorporar uma componente de arte, história de arte e estética, como forma de construir a mudança, aqui e agora. Mais ainda, esta análise artístico-histórica deve simultaneamente incluir a compreensão da inter-relação, dentro da cultura, das estruturas patriarcais e capitalistas, reconhecendo o carácter político da arte (Lippard, 1981/2006), não esquecendo, todavia, a relação entre o "eu" e o "Outro", nas suas especificidades, também femininas, constituindo a experiência estética um contributo relevante para pensar essa relação. Parafraseando Deborah Haynes (1997: 48), "a arte é uma poderosa ferramenta para a mudança das consciências e para a criação da mudança social”.

\section{Referências bibliográficas}

Barreno, Isabel, (1985), O falso neutro. Lisboa: Edições Rolim.

Benjamin, Walter (2004), A modernidade. Lisboa: Assírio e Alvim.

Broude, Norma; Garrard, Mady D. (orgs.) (1994), The Power of Feminist: The American Movement of the 1970s, History and Impact. New York: Harry N. Abrams. 
Chadwick, Whitney (1996), Women, Art, and Society. London: Thames and Hudson. Cixous, Hélène (1975/2006), "The Laugh of the Medusa", in Hilary Robinson (org.) (2006), Feminism-Art-Theory: An Antbology 1968-2000. Oxford: Blackwell Publishing, 102-106.

Coimbra, Artemisa (2008), "Crónicas de Mortes Anunciadas”. Dissertação de Mestrado em Ciências da Educação, Faculdade de Psicologia e Ciências da Educação, Universidade do Porto.

Cornell, Drucilla (2009), Clint Eastwood and Issues of American Masculinity. New York: Fordham University Press.

Cruz, Angélica; Magalhães, M. José (2009), "Susana e os velhos: tema recorrente na arte e na vida”, in Anabela Moura (org.) (2009), Diálogos com Arte. Braga: CESC e UM.

Cruz, Angélica (2002), "Clay Figurines of Galegos: An Anthropology of Artistic Production made by Women in Northern Portugal”. Tese de Doutoramento, Universidade de Surrey Roehampton, Londres.

Dickson, Anne (2003), A Voice for Now: Changing the Ways We See Ourselves as Women. London: Piatkus.

Freeland, Cynthia (2001), But Is It Art? Oxford: Oxford University Press.

Foucault, Michel (2001), The Order of Things: Archaeology of the Human Sciences. Londres: Routledge.

Fraser, Nancy (1995), "What's Critical about Critical Theory: The Case of Habermas and Gender”, in Johanna Meehan (org.), Feminists Read Habermas: Gendering the Subject of Discourse. London: Routledge.

Frow, John (1995), Cultural Studies \& Cultural Value. Oxford: Clarendon Press.

Garrard, Mary (1982), “Artemisia and Susanna”, in Norma Broude; Mary D. Garrard (orgs.), Feminism and Art History: Questioning the Litany. New York: Harper \& Row.

Giddens, Anthony (1991), Modernity and Self-Identity: Self and Society in the Late Modern Age. Cambridge: Polity Press.

Greer, Germaine (1979), The Obstacle Race: The Fortunes of Women Painters and Their Work. New York: Farrar Straus \& Giroux.

Grosenick, Uta (2001), Mulheres artistas nos séculos XX e XXI. London: Taschen.

Hagen, Rose-Marie; Hagen, Rainer (2004), Francisco de Goya. Köln: Taschen - Público.

Hall, Stuart (1997), Representation: Cultural Representations and Signifying Practices. Culture, Media and Identities Series. London: Open University e Sage Publications. Harris, Jonathan (2001), The New Art History. A Critical Introduction. London: Sage. Hatty, Suzanne (2000), Masculinities, Violence and Culture. Sage Series on Violence against Women. London: Sage.

Haynes, Deborah J. (1997), The Vocation of the Artist. Cambridge: The University Press. hooks, bell (1995), Art on My Mind. Visual Politics. New York: The New Press.

La Belle, Thomas J. (1986), Non Formal Education in Latin America and the Caribbean. Stability, Reform or Revolution? New York: Praeger. 
Labowitz-Starus, Leslie; Lacy, Suzanne (1978/2006), “In Mourning and In Rage...”, in Hilary Robinson (org.), Feminism-Art-Theory: An Anthology 1968-2000. Oxford: Blackwell Publishing, 102-106.

Lippard, Lucy (1995), The Pink Glass Swan: Selected Feminist Essays on Art. New York: The New Press.

Lippard, Lucy (1981/2006), "Hot Potatoes: Art and Politics in 1980", in Hilary Robinson (org.), Feminism-Art-Theory: An Anthology 1968-2000. Oxford: Blackwell Publishing, 107-118.

Magalhães, Maria José (2007), "Agência feminista e das mulheres: procurando o novo sujeito feminista?", in Lígia Amâncio et al. (orgs.), O longo caminho das mulheres. Feminismos 80 anos depois. Lisboa: Dom Quixote, 229-244.

Magalhães, Maria José (2005), "Mulheres, Espaços e Mudanças: o pensar e o fazer na educação das novas gerações”. Tese de Doutoramento em Ciências da Educação, Faculdade de Piscologia e de Ciências da Educação da Universidade do Porto. Magalhães, Maria José (2003), "Em torno da definição do conceito de agência feminista”, ex aequo - Revista da Associação Portuguesa de Estudos sobre as Mulberes, 8, 5-12.

Marshall, Barbara (1994), Engendering Modernity: Feminism, Social Theory and Social Change. New Hampshire: Northeastern.

Nochlin, Linda (1989), "Why Have There Been No Great Women Artists?”, in Women, Art, and Power and Other Essays. London: Thames and Hudson (originalmente publicado na Art News, 69, Janeiro, 1971).

Parker, Rozisca; Pollock, Griselda (1981), Old Mistresses: Women, Art and Ideology. London: Pandora Press.

Pateman, Carole (2003/1988), “O contrato sexual: o fim da história?”, ex aequo - Revista da Associação Portuguesa de Estudos sobre as Mulberes, 8, 31-43.

Pinto, Helena; Brasil, Elisabete; Fonseca, Laura; Magalhães, Maria José (2004), "Violência contra as Mulheres e Família”, comunicação apresentada ao V Congresso da Associação Portuguesa de Sociologia, "Sociedades contemporâneas: reflexidade e acção”, Braga, 12 a 15 de Maio de 2004.

Pinto, Helena; Brasil, Elisabete; Magalhães, Maria José; Fernandes, Laura (2002), "ONGs de mulheres e a luta contra a violência contra as mulheres e crianças no seio da família: o contributo da UMAR”, in Actas do Colóquio Família, Género e Sexualidades nas Sociedades Contemporâneas, Associação Portuguesa de Sociologia.

Pollock, Griselda (1982/88), "Vision, Voice and Power: Feminist Art Histories and Marxism", in Vision and Difference: Feminity, Feminism and the Histories of Art. London: Routledge [publicado originalmente em Block, 6, 1982].

Pollock, Griselda (2001), "Modernity and the Spaces of Femininity”, in Francis Frascino; Jonathan Harris (orgs.), Art in Modern Culture: An Anthology of Critical Texts. London: Phaidon. 
Pollock, Griselda (2007), “O Feminismo: un Fenómeno Mundial que Chegou ata a Universidade. Reflexións sobre a Influencia do Feminismo no Pensamento e a Arte desde 1970", in A Batalla dos Xéneros, Catálogo da Exposição de 13 de Setembro a 9 de Dezembro 2007, Junta de Galicia, 99-104.

Sandlos, Karyn (2000), "Unifying Forces: Rhetorical Reflections on a Pro-choice Image”, in Sara Ahmed et al. (orgs.), Transformations. Thinking Through Feminism. London: Routledge, 77-91.

The Boston Women's Health Book Collective (1996), The New Our Bodies, Ourselves: A Book by and for Women. Preface by Byllye Avery, Helen Rodriguez-Trias and Gloria Steinem. New York: Simon \& Schuster.

\section{Referências electrónicas}

Guerrilla Girls, http://www.guerrillagirls.com/posters/advantages.shtml, consultada em 27/01/2010.

Guerrilla Girls, http://www.guerrillagirls.com/posters/getnaked.shtml, consultada em 27/01/2010.

Magalhães, Maria José (2005), “A violência nas relações de intimidade: um contributo para a definição de alguns conceitos”, http://www.umarfeminismos.org/images/ stories/pdf2/ViolenciaConceitosMJM2005.pdf, consultada em 27/10/2010.

UMAR (2009), http://www.umarfeminismos.org/index.php?option=com_content\&vie $\mathrm{w}=$ article\&id=48\&Itemid=35\&limitstart=6, consultada em 22/12/2009.

UMAR, http://www.umarfeminismos.org/index.php?option=com_content\&view=arti cle\&id=48\&Itemid=35\&limitstart=3, consultada em 22/12/2009.

The New Our Bodies, Ourselves, http://books.google.pt/books?id=xlx94hWpe6YC\& $\mathrm{pg}=\mathrm{PA} 408 \& \mathrm{lpg}=\mathrm{PA} 408 \& \mathrm{dq}=$ geraldine + santoro + abortion $+\mathrm{mrs}+$ magazine $\&$ source =bl\&ots=yGLjTHimak\&sig=Vg62o7qHoMBb5_ZvnJy8dUEJ9Xw\&hl=pt-PT\&ei=$-\# \mathrm{v}=$ onepage\&q\&f=falsebJaTNj3HNiJOM2M5MkP\&sa=X\&oi=book_result\&ct=r esult\&resnum $=7 \& v e d=0 C D c Q 6 A E w B g \# v=$ onepage $\& q \& f=$ false ()

\section{Créditos das imagens}

Fig. 1: Goya, Eles levaram-na (Série Caprichos), 1797-1798

Fig. 2: Leslie Labowitz e Suzanne Lacy (1977), In Mourning and in Rage, Los Angeles Foto de Maria Karras

Fig. 3: Paula Rego, Sem título, 1998

Fig. 4: Anónima (2001-2002), O Meu Corpo Pertence-me 